\title{
LEARNING FROM ITIL FOR EFFICIENT INTERNAL SERVICES OF AUTHORITIES
}

\author{
Anne Diedrichs ${ }^{1}$
}

DOI: 10.24989/ocg.v.338.6

\begin{abstract}
In the following, we highlight why IT Infrastructure Library (ITIL) proposals, which have long been established for the management of IT services [8], can add value to the management of services offered by the Internal Services division of authorities.

The Internal Service divisions of authorities offer a wide range of services that may differ from one authority to another. However, as a rule, the following services are offered as core offers:

- Mail processing, messenger service, document creation and management, duplication and printing, e.g. business cards.

- $\quad$ Facility management including winter maintenance and cleaning of buildings, access control and security, vehicle availability. However, facility management is usually a major part of provided internal services.

- $\quad$ Procurement and internal materials management, more and more as the implementation of decentralized activities of the consolidated processes.
\end{abstract}

Adapting methods and procedures from ITIL can help to provide an overview about all offered internal services and makes the point of contact transparent for each of them. Furthermore, implementing support systems following that idea generate necessary information for keeping track of individual service requests. Hereon, even online steering mechanisms become possible as it is standard for IT services as of today.

\section{Introduction and questioning}

The Internal Services division of public administrations offers a wide range of services, which may vary from one authority to another. As a rule, however, the following services are offered as core offerings:

a) "Mail processing, messenger service, document creation and management, duplication and printing.

b) Access control and security services, procurement and internal materials management.

c) Car pooling and facility management (e.g. winter maintenance and cleaning)“. [1]

In this context, facility management usually represents an extensive subdivision of the Internal Services division.

\footnotetext{
${ }^{1}$ Hochschule des Bundes für öff. Verwaltung, Fachbereich Finanzen, Studiengang Verwaltungsinformatik, Gescherweg 100, 48161 Münster, Germany, anne.diedrichs@vit-bund.de,www.vit-bund.de
} 
This means that the area covers a broad, rather heterogeneous spectrum of tasks. All these tasks have in common, however, that they represent services that are primarily aimed at the employees of the authority itself. These are so-called support processes for the authority. For authority employees who are finally the addressees or users of the services offered by the Internal Services devision - the department is often rather non-transparent from the outside. In some cases, users are not able to see directly which services are actually offered for them.

In a second step, users often need to research which contact person or which of several hotlines or service numbers is the right addressee to contact for their respective request. Once the request has finally been successfully put on the right track, the user often is not able to follow the status of his/her request.

Especially for the Internal Services division, it is often a special challenge to appear outwardly as one service unit and to create internally transparency and consolidated process structures.

In the following we will show why the use of the IT Infrastructure Library (ITIL), which has long been established for the management of IT services [8], adds value for the management of the services offered by the Internal Services division. This work focuses on the service desk and the service catalogue.

\section{Fundamentals}

In the current literature the term Enterprise Service Management is currently being formed. There is as yet no officially adopted definition of this term[3, p. 7]. One suggested definition is that this can be understood as "a strategic and structured extension of proven IT technologies and processes of IT service management to non-IT parts of the company"[3, p. 9]. Hennhöfer[3, p. 9] writes: „ESM [Enterprise Service Management] is a strategic approach to applying a service-oriented business model to the internal mode of operation of an organization. It is an operational architecture model in which each functional area of an organization that provides internal services is defined as a service domain. The actual services provide results for other functional areas. These in turn deliver results for external customers - the actual business model of the organization.

Basically, ESM is about simplifying and standardizing internal workflows, automating them where possible and making them traceable and measurable. Properly implemented, Enterprise Service Management can accelerate business processes, increase the productivity and profitability of the organization - and ensure satisfied employees.“

Tisson [11, p. 245] describes „Enterprise services as the exchange of services between companies, customers and suppliers on the market and as the result of internal service processes“".

Maurer [6] also defines ESM via ITSM. He writes: "It makes sense to also digitalize and offer standardized and (partially) automated services for departments such as HR, marketing or sales. Examples include electronic personnel files or automated lead and campaign management. In this case ITSM becomes the more comprehensive ESM".

There are suitable tools on the market not only to map IT service management processes and functions, but enterprise service processes in general [7]. So, ITSM tools are available, that explicitly address areas of application such as facilities management or personnel management[5, p. 13]. 
It is notable that, when researching the keyword Enterprise Service Management, just few scientific publications on the topic can be found, compared to several market providers from the ITSM, sector who have already extended their tools for Enterprise Service Management.

\section{Study on first adaptions from ITIL}

Our evaluation of business distribution plans of state and federal authorities has shown that in most authorities the Internal Service division is organised in one unit. In many cases, this is also called "Internal Services" or has comparable names such as "Central Services" or similar. In a few authorities, the area is divided into several sub-areas in organisational terms. Irrespective of the organisational form, requests concerning services from the employees of the authorities - the customers of the services - can, in our experience and research, rarely be addressed via a central telephone number or a central portal. Instead, in most cases separate telephone numbers or named contact persons are given for each sub-area - e.g. in the business distribution plan. In some cases, there are already existing service points for parts of the area. However, it is not uncommon for users to have to "ask their way". In order to improve this situation, a service desk implementation seems to be a first useful adaption from classic ITSM.

\subsection{Service Desk}

In IT Service Management according to ITIL, the so-called Service Desk represents an essential function. It is the single point of contact between users and the IT organization. Users should contact the Service Desk for all requests concerning IT matters. This includes in particular incident reports and the addressing of so-called service requests. This is because the ITIL-based service desk, as a service functional unit, primarily provides first-level support for the incident management and request management practices. In order to be able to adequately answer or process the wide range of user queries, the Service Desk employees are integrated into the IT processes as follows:

- $\quad$ First of all, of course, they know all the services that the IT sector offers.

- They know the service level agreements on which the services are based.

- They are informed about maintenance windows and upcoming changes such as new releases.

- They provide users (ideally proactively) with information on the processing status of their request and are corresponding involved in the processing information flow.

- In a best-case scenario, they can completely process some of the incidents, service requests, and possibly other issues themselves.

One goal is to ensure that the service desk represents the IT area to the outside world well. Another goal is to build up sufficient expertise in the Service Desk so that users prefer to call it, rather than asking a colleague directly ("hey-Joe principle"). For the IT department itself, the Service Desk also has several advantages [10, p. 182]:

- Since the Service Desk is always tool-bound, statistics can be called up at relatively short notice, e.g. an overview of which service has had the most problems in the past month or which services are particularly in demand.

- It is also tool-based and thus verifiable whether service levels have been maintained, if so which ones have been agreed. At least it is easy to determine how long it took on average to process a particular incident.

- It is easy to generate an overview of which incidents and service requests are still open. 
- With the help of a central service desk, it is possible to find out relatively quickly whether users are affected by a whitespread incident.

- No requests are lost or forgotten.

- Structured processes with clear responsibilities lead to improved teamwork and better communication within the IT service.

- $\quad$ And last but not least: Competent IT specialists can deal with a problem without being interrupted by user calls again and again, since the Service Desk employees are responsible for communication with the users.

Just as in the IT service area, the Internal Services receive requests of the same structure. Users want to report incidents here and there, receive information or inquire about services offered. Examples of incidents in the Internal Service area could be, for example:

For the area of the Internal Service designated above under a)

- $\quad$ non picked up post

- the failure of a plotter/copier

For the area of the Internal Service designated above under b)

- $\quad$ a broken office chair

For the area of the Internal Service designated above under c)

- $\quad$ central failures of the building services (electricity, heating) or

- local faults such as a defective office lamp, a defective tap, defective sanitary facilities or missing soap/towels in the sanitary facilities

The decisive factor here is first and foremost which services the Internal Service provides for users. Examples of service requests from the Internal Service could be:

For the area marked a) above:

- A duplication order.

For the area marked b) above:

- $\quad$ Order of office supplies from a product portfolio offered

For the area marked c) above:

- $\quad$ Order of the transport service or a vehicle for a business trip

- Booking a conference room

In principle, the same advantages that a central service desk offers for the IT area - namely essentially user-friendliness, relief of the service area internally and the efficient acquisition of management information - would also result for the internal service area. However, an essential feature of a Service Desk according to ITIL is its integration into the ITIL process landscape. A service point that works 
largely isolated from the rest of the service area would not be a service desk in the sense of ITIL. Nor would a Service Desk in the sense of ITIL be a Service Point in the midst of processes, none of which are based on the Service Management approach of ITIL. At least one incident handling process based on the Incident Management process should already be in place or should be introduced parallel to the Service Desk. In another study it has already been shown that a process based on Incident Management could be adapted to the area of Internal Services [2].

\subsection{Service catalog - customer view}

For a Service Desk to work well, users and Service Desk staff need to know the services offered. In the field of IT, the so-called service catalog according to ITIL can serve this purpose: "The service catalog is part of the overall service portfolio in the form of a database or a structured document with information on all live IT Services, including those services that are available for deployment" [4, $\mathrm{p}$. 61]. By means of a service catalogue, transparency is created for users which services the service area offers for them. However, the service catalog goes far beyond a rudimentary list of responsibilities in a business distribution plan. It lists the individual services offered in a level of detail that is oriented towards the user, and indicates which approval processes an order must go through and when the result can be expected. In principle, a service catalogue is possible for all service areas, including internal services. In the Internal Services area, it could contain the following information, for example:

For the area marked a) above:

- With how much lead time must a print job be submitted? Can special orders such as large colour plates or similar be processed? What does the approval process look like?

For the area marked b) above:

- $\quad$ Are there different chair models or high desks for office equipment? What does the application process for this look like?

For the area marked c) above:

- In which cases can the transport service be ordered and how many days/hours in advance must the demand be announced?

All this can be made transparent to users via the service catalogue. Via single sign-on, identified users can view the service catalogue tailored to their individual needs. According to original ITIL literature, "the service catalogue acts as a procurement portal for customers and contains not only price information but also service level obligations and conditions for service provision [4, p. 113].

At present, users in many authorities still have to ask for this information individually, if it is known at all. A lot of time is lost in this process, both the working time of the users and the working time of the employees of the internal services.

\subsection{Service catalogue - from service organisation perspective}

Apart from that, the service catalogue is also a support for the service area itself that should not be underestimated: The service catalogue also provides employees in the service area with an overview 
of all services offered from their department. However, the support of the service area through the service catalog goes far beyond an overview for information purposes. The service catalog according to ITIL has an internal view of the services in addition to the user view towards the customer - the so-called customer-oriented services [4, p. 111]. These are services that run in the background usually invisible to the user. These are sometimes outsourced in whole or in part to service providers - be they external or internal service providers. The existing Operational Level Agreements (OLAs, agreements between work areas of the same authority) or Underpinning Contracts (UCs, contracts with third parties) are described, but also the required components [4, p. 115].

What could be supportive services in the area of internal service? In the area of the motor pool, a supporting service would be, for example, the maintenance of the vehicles. One component would be, for example, an IT-supported vehicle management and booking tool, which is generally being used in this area. This in turn has to be operated. There can either be an agreement with the internal in-house IT or an external service contract (or both).

In the area of building management, the supporting services could include the cleaning service, perhaps also the delivery or procurement service for new towels, soap, and so on. Probably there is also a maintenance or service contract for the heating system.

In the area of duplication and printing, supporting services would be, for example, the maintenance of the plotters and the supply of new plotter cartridges and printer paper.

\subsection{Service catalogue - creation}

Creating a service catalogue for a service area is certainly not trivial. Even the question of what a service is "cannot be answered as easily as it may seem at first glance" [4, p. 111]. "Every organization must develop a policy for what a service is and how it should be defined and agreed upon. As a first step, in many cases a survey of customers is helpful to find out what services they use and how these services are aligned with and support business processes" [4, p. 111]. This information, together with the existing knowledge of the service area itself, forms the basis for a strategic assessment as to whether services should continue to be offered in the current scope. An inventory and evaluation helps to identify services that are offered but for which there is little or no demand. Sometimes it is found that it makes sense to revise and adapt services in the light of current developments or to think about completely new services. In principle, ITIL recommends that you evaluate services not only once when you first create a service catalog, but on an ongoing basis. The help of the users is also sometimes required when it comes to using user-oriented terms for the services offered. This ensures that the service catalog is accepted by the users later on.

\subsection{Request and incident models to supplement the service catalogue}

The service catalogue clearly shows the customer which services are offered and how they can be ordered. The internal view of the catalogue gives the staff of the Internal Services devision information about the supporting services. To process a service request, ITIL also recommends creating a so-called request model for each request. Such a model contains a "standard process flow as well as the roles and responsibilities" [10, p.108-109]. Before a service is added to the service catalog, the corresponding request model should be created. This is possible because service requests can be completely planned from the start. 
For the Internal Services devision, a service request could be a print job in the print shop. As an example, a cost-intensive print on a DIN-A-0 Kapa plate is to be ordered. In the service catalogue, it is transparent for the user who wants to order this plate whether and, if so, which approvals are required. Ideally, the approval workflow is tool-supported and the user can trigger the order immediately via the service catalog.

For example, the request would be submitted electronically via the supervisor and/or the responsible cost center. The printing company would receive the print job that has already been approved, would execute the print job within the agreed time, reorder material if necessary, carry out the necessary documentation and communicate the status as agreed.

For the area of Incident Management, the creation of Incident Models for recurring incidents is useful. However, it is not possible to create an incident model in advance for every incident in the IT area, since incidents cannot be planned and predicted completely. However, for some incidents - just those incidents that "concern an event that has already occurred in the past and can occur again at any time" $[10$, p. 86$]$ - it is possible to create a model. For example, it would be conceivable to create an incident model in the Internal Services devision for the incident "Heating does not work as intended" and store it in the Service Desk. This would record the recommended process run-up in the event of a malfunction.

As an example, the following could be illustrated: who is responsible first, which heating parameters are to be checked, who is to be informed by whom next and by what means, etc. The internally agreed reaction and recovery times are also relevant here. An incident model for the malfunction of a nonfunctioning luminaire is also conceivable. In many cases, this malfunction can be safely remedied by replacing a lamp. Even if such a replacement seems simple at first glance, it is helpful to go through the process of the case of the defect and the steps to be taken and record them in an incident model. Such a model would then record who is responsible, which room-specific features exist, when new lamps have to be ordered, whether and what recovery times have been agreed and what has to be done if the lighting still does not work despite the replacement of the lamp and, last but not least, how the flow of information and documentation has to be carried out.

\section{Consolidation of IT- and Internal Services}

It is not always obvious to the user whether IT or Internal Services is the right addressee for a request. One area for which both, Internal Services and IT, can be responsible, is the area of copy printers in the sense of multifunctional devices. In the event of a fault, it is not always clear to the user what the exact cause of the fault is and which unit should be contacted accordingly. In the worst case, the user is referred from contact person to contact person. In our experience, both areas can be responsible for replacing a printer cartridge or for questions regarding printer functionality, depending on the area of responsibility of the printer. The IT department is usually responsible for the connection to the client. However, in the event of an error it is usually only clear to the user that the printer will not print for reasons that are not transparent to him.

A similar situation can often be found in the field of electronic media equipment for classrooms or meeting rooms. Smartboards can be procured by the Internal Services, the connection of the smartboards to the client is usually done by IT. If the media architecture does not function properly, the cause of the error is usually not transparent for the user and it is therefore unclear whom to contact. 
The mentioned overlapping of responsibilities is not a marginal phenomenon, as our experience shows that the number of fault reports for printers is not negligible.

In the sense of a user-oriented view, it could therefore be useful in the future to create a joint service catalogue for the two service areas Internal Services and IT. For this purpose, both areas do not necessarily have to be organizationally combined in a joint service department.

A common external presentation of the service catalogues is possible, for example, via a portal. In order to ensure a uniform presentation of the catalog both externally and internally, the departments must coordinate their activities accordingly. This can be done, for example, as part of a joint project.

In this context, interfaces between the two areas should also be identified and agreed upon - if not already done sufficiently - and corresponding responsibilities should be defined. In a first step, clear internal support agreements between the service departments must be made before a joint service catalogue is created in a second step in the interest of user-friendliness. Accordingly, the request and incident models would also be modeled across departments.

It would certainly be convenient for users to have to remember just one service number, service email address, or service portal and then be supported by a joint service desk competently, through which all inquiries concerning Internal Services and IT are jointly managed. This is only possible to a limited extent with organizationally separate service units, since a service desk means much more than just a common telephone number, but also and especially the integration into the service processes.

\section{Summary}

The preceding investigations have shown that the ITIL constructs Service Desk and Service Catalogue, extended by Request and Incident models, can be adapted with added value to the area of Internal Services. A common idea of service management of the Internal Service and IT departments would not only help the users but also both departments themselves, especially when it comes to handling cross-departmental incidents efficiently and in a customer-oriented manner.

Further work of evaluation needs to be done about the implementation using IT tools, and furthermore, whether such an approach is in practice really more efficient compared to the current way of work.

Besides, work covering the increase of organizational governance needs to be conducted.

\section{Literature}

[1] Bundesrechnungshof, Bemerkungen 2011 zur Haushalts- und Wirtschaftsführung des Bundes, Abschnitt 6.1, p. 132

[2] DIEDRICHS, A., (2019), Möglichkeiten der Adaption von ITIL V3® für den Bereich Innerer Dienst. Eine Untersuchung am Beispiel der Lifecycle Phase Service Operation. Festschrift 40 Jahre Fachbereich Finanzen 
[3] HENNHÖFER, F., (2017), Enterprise Service Management als Treiber der digitalen Transformation. IT Service Management Nr. 42, pp 6-9.

[4] HUNNEBECK, L. and ORR, A. T., (2013), ITIL Service Design, Axelos 2013

[5] KEMPTER, S., (2017): Enterprise Service Management nimmt Fahrt auf. it Service Management Nr. 42, pp 13-14.

[6] MAUERER, J., (2019), Enterprise Service Management steht erst am Anfang. Computerwoche IDG, https://www.computerwoche.de/a/enterprise-service-management-steht-erst-am-anfang, 3546424. Zugriffen: 12.01.2020.

[7] MENDEL, Th., (2017), IT- und Enterprise Service Management: Das sind die Top-Anbieter in Deutschland. IT Service Management Nr. 42, pp 24-29.

[8] POTGIETER, B. C., BOTHA, J. H. and LEW, C., (2004), Evidence that use of the ITIL framework is effective. National Advisory Committee on Computing Qualifications , 17 ; pp $161-168$

[9] RANCE, S. and ORR, A. T., (2011), ITIL Service Transition, Axelos 2011

[10] STEINBERG, R. A. and ORR, A. T., (2013), ITIL Service Operation, Axelos 2013

[11] TISSON, H., (2019), Enterprise-Service-Management. Strategie und Transformation im digitalen Zeitalter, Springer Fachmedien Wiesbaden. 